Ann. Biol. anim. Bioch. Biophys., I964, 4 (I), 79-9o.

\title{
ACTION DE L'ACIDE ACÉTIQUE ET DE L'ACIDE TRICHLORACÉTIQUE SUR LA CASÉINE ( $\left.{ }^{1}\right)$
}

\author{
Ch. ALAIS $\left({ }^{2}\right)$ et P. JOLLÈS \\ avec la collaboration technique de Nelly Berthelot \\ Institut de Biochimie, Faculté des Sciences de Paris, Centre d'Orsay, Orsay (Seine-et-Oise) \\ et Laboratoire de Chimie biologique de la Faculté des Sciences, Paris
}

SOMMAIRE

Lorsque l'on précipite différentes caséines de leur solution, en abaissant le $\mathrm{pH}$ à 4,6 par addition d'acide acétique, et lorsqu'on les précipite par l'acide trichloracétique à i $2 \mathrm{p}$. roo de concentration finale, des substances peptidiques restent en solution. Leur proportion dépend de l'espèce de caséine et des conditions de l'expérience. La caséine $x$ est le constituant de la caséine entière de vache le plus sensible à l'action des réactifs acides.

A partir de la caséine $x$, les substances peptidiques solubles se forment à nouveau au cours d'un deuxième traitement. On peut trouver des analogies entre certaines de ces substances, d'une part, et les produits de la réaction de la présure sur la caséine $x$ d'autre part. Cependant, la faible teneur en glucides des substances solubles dans les réactifs acides et surtout le fait que la caséine $x$ résiduelle subit normalement l'action de la présure, (elle n'a pas été transformée en paracaséine au cours des précédents traitements), montrent que l'on ne peut assimiler l'action de ces réactifs à celle de la présure sur la caséine $x$ originelle.

\section{INTRODUCTION}

Ia caséine est par définition la substance protéique qui précipite lorsqu'on acidifie le lait frais; la précipitation atteint un maximum à $\mathrm{pH} 4,6$. Le premier auteur qui ait clairement décrit la préparation de 1a caséine est QUEVENNE (I84I); il effectuait la précipitation par l'acide acétique. La méthode a été codifiée par HAMMARSTEN (I874), qui utilisait le même acide. On emploie encore aujourd'hui cette

(1) Une partie de ces recherches a été présentée dans une thèse soutenue par l'un de nous (C. ALAIs) devant la Faculté des Sciences de Paris (1962).

${ }^{2}$ ) Chercheur contractuel de l'Institut national de la Recherche agronomique, C. N. R. Z., Jouy-enJosas (S.-et-O.). 
méthode, en utilisant différents acides organiques (acétique, lactique...) ou minéraux (chlorhydrique, sulfurique...). Quoi qu'il en soit, il y a nécessairement un contact plus ou moins long entre la protéine et un acide, à $\mathrm{pH}_{4}, 6$.

La dégradation de la caséine par les réactifs acides a été envisagée par HAMMARSTEN (I876), pour réfuter l'existence d'espèces protéiques douteuses dans le lait, comme la " lactoprotéine " ou la "galactine ". Récemment BEEBY et NITSCHMANN (I963) ont étudié l'effet de la précipitation de la caséine à $\mathrm{pH} 4,6$, par l'acide chlorhydrique, et ont observé la séparation d'une fraction glycopeptidique.

I'acide trichloracétique (TCA) est le réactif le plus utilisé pour la précipitation des protéines du lait. RowLAND (I938) a discuté des avantages et des inconvénients de plusieurs réactifs déprotéinisants (acides trichloracétique et phosphotungstique, tungstate de sodium, acétate d'uranyle) et a finalement choisi l'acide trichloracétique à la concentration finale de $\mathbf{I} 2 \mathrm{p}$. Ioo. C'est ce même réactif que nous avons utilisé au cours de l'étude de l'action protéolytique de la présure sur diverses caséines (AlaIs et al., I953; AlaIs, I963) et au cours de la préparation du caséino-glycopeptide (ou "NPN-I2 p. Ioo-TCA ") (AlAis et Joliès, I96I). Dans la communication précédente, nous avons souligné le fait que la proportion d'azote non protéique (NPN) soluble dans TCA à I2 p. IOo, avant 1'action de la présure, était loin d'être négligeable, et devait être prise en considération dans 1'interprétation des résultats.

Nous exposerons ci-après les résultats de nos recherches sur la libération de substances peptidiques par des réactifs acides agissant sur diverses caséines et principalement sur la caséine $x$ de vache, et nous les interpréterons en tenant compte des propriétés de cette dernière protéine et en particulier de la réaction de la présure.

\section{MATÉRIEI, ET TECHNIQUES}

\section{Substrats}

Les caséines entières du lait des ruminants sont obtenues par précipitation du lait frais et écrémé, à $\mathrm{pH} 4,6$, par $\mathrm{HCl} \mathrm{N}$; le précipité est abondamment lavé à l'eau puis redissous dans $\mathrm{NaOH} \mathrm{N}$; la caséine est reprécipitée de la solution par $\mathrm{HCl} \mathrm{N}$, lavée à l'eau, à l'alcool et à l'éther ; la prépara. tion de la caséine humaine exige des précautions particulières qui ont été précédemment décrites (Alais et Jollès, I962).

La caséine $\alpha$ de vache est obtenue par fractionnement de la caséine entière au moyen de l'urée, selon Hipp et coll., (I952) et la caséine $x$ de vache, par fractionnement au moyen de $\mathrm{CaCl}_{2}$ et de l'éthanol selon McKenzie et Wake (1961).

\section{Méthodes analytiques}

Le dosage de l'azote a été effectué par micro-Kjeldhal, dans les solutions de caséine et dans les filtrats obtenus après l'action du réactif acide ; les conditions d'action sont précisées pour chaque expérience. La proportion d'azote non protéique (NPN) formé est exprimée en p. Ioo de l'azote de la solution initiale de caséine ( $\mathrm{N}$-caséine).

Dans les substances NPN sèches, on a dosé les osamines par la méthode de RondLE et MORGAN (I955), les sucres réducteurs par la méthode de SchulTze et coll., (I958), l'acide sialique par la méthode à l'acide thiobarbiturique de WARREN (I959), après hydrolyse par l'acide sulfurique o,I N.

Les acides aminés ont été déterminés au moyen de l'analyseur automatique "Technicon ", à partir de $2 \mathrm{mg}$ de substance NPN ayant subi une hydrolyse acide totale ( $\mathrm{HCl} 6 \mathrm{~N}, 110^{\circ}, 24 \mathrm{~h}$ ). Nous avons employé la technique d'élution de PiEz et Morris (Ig60).

Les substances NPN sèches ont été obtenues par lyophilisation. Une partie de ces substances a préalablement subi une dialyse prolongée (6 jours). 


\section{Examens électrophorétiques}

Ils ont été effectués sur bande de papier Whatman $n^{\circ}$ I, dans le tampon volatil pyridine-acide acétique-eau (I00:4:900, v/v) à $\mathrm{pH} 6,5$, pendant 2 heures, avec un gradient de potentiel de 15 volts $/ \mathrm{cm}$. La révélation a été faite par coloration à la ninhydrine ou au vert de lissamine.

\section{RÉSULTATS}

\section{I. - PROPORTION D'AZO'TE NON PRO'TÉIQUE (NPN) LIBÉRÉ PAR LES RÉACTIFS ACIDES}

Nous avons fait agir sur les solutions de caséines, l'acide acétique en quantité juste suffisante pour abaisser le $\mathrm{pH}$ de 6,8 à 4,6 et 1'acide trichloracétique pour avoir une concentration finale de 2 ou de $\mathrm{I} 2$ p. Ioo. La proportion de NPN, exprimée en p. roo de l'azote de la caséine, dépend de l'espèce de caséine, du réactif et aussi, quoique moins fortement, de la concentration de la solution protéique.

\section{TABLEAU I}

Proportion de NPN avec différentes caséines

( $\mathrm{N}$ soluble p. roo de $\mathrm{N}$-caséine)

\begin{tabular}{|c|c|c|c|}
\hline \multirow{2}{*}{ Caséines * } & \multirow{2}{*}{$\begin{array}{l}\text { A pII } 4,6 \\
\text { (avec l'acide } \\
\text { acétique } \mathrm{N} \text { ) }\end{array}$} & \multicolumn{2}{|c|}{$\begin{array}{l}\text { Avec l'acide trichloracétique } \\
\text { à la concentration finale }{ }^{* *} \text { de }\end{array}$} \\
\hline & & $2 \mathrm{p} \cdot 100$ & $\begin{array}{l}12 \text { p. } 100 \\
(\mathrm{NPN}-\mathrm{O})\end{array}$ \\
\hline Caséine de vache & & & \\
\hline Caséine entière $\ldots \ldots \ldots \ldots \ldots \ldots \ldots \ldots$ & 0,85 & 0,30 & 0,13 \\
\hline 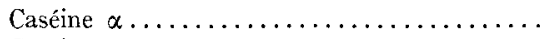 & 0,75 & 0,30 & 0,12 \\
\hline Caséine $x \ldots \ldots \ldots \ldots \ldots \ldots \ldots \ldots \ldots \ldots$ & 6,00 & 2,50 & 0,75 \\
\hline Caséine entière de brebis .............. & 0,70 & & 0,20 \\
\hline Caséine entière de chèvre...$\ldots \ldots \ldots \ldots$ & 0,65 & & 0,17 \\
\hline Caséine humaine entière $\ldots \ldots \ldots \ldots \ldots \ldots$. & 6,40 & & 1,80 \\
\hline
\end{tabular}

* Solutions à $1,2-1,5$ p. 100 de caséine, à pH 6,8, préparées juste avant l'expérience. caséine.

** 1 volume de solution d'acide trichloracétique à 4 ou à $2^{\prime} t$ p. 100 ajouté à 1 volume de solution de

Le tableau I présente les résultats obtenus à partir de 6 caséines en solutions ayant des concentrations voisines ( $I, 2$ à I,5 p. IOO). On voit que la solubilité apparente des caséines entières des ruminants est faible. Par contre la caséine entière humaine et la caséine $x$ de vache donnent des proportions de NPN relativement élevées, surtout à $\mathrm{pH} 4,6$. 
I e NPN soluble dans TCA à I2 p. Ioo (nous l'avons précédemment appelé " NPN-O ») représente en moyenne I5 p. Ioo du NPN soluble à $\mathrm{pH} 4,6$ avec les caséines de vache, et 28 p. Ioo avec les autres caséines. Il y a donc une proportion importante des substances solubles à $\mathrm{pH} 4,6$ qui sont insolubles dans 'TCA.

La proportion de NPN soluble dans TCA à I2 $\mathrm{p}$. Ioo s'accroît au cours du vieillissement de la solution de caséine entière, bien que la conservation ait lieu à basse température $\left(+3^{\circ}\right)$ et en présence de toluène $(0,05 \mathrm{p}$. IOo) ; c'est ce que montre le tableau 2, pour trois solutions à différentes concentrations.

\section{TABLEAU 2}

Variation de la proportion de NPN en fonction du temps

(N soluble p. roo de $\mathrm{N}$-caséine)

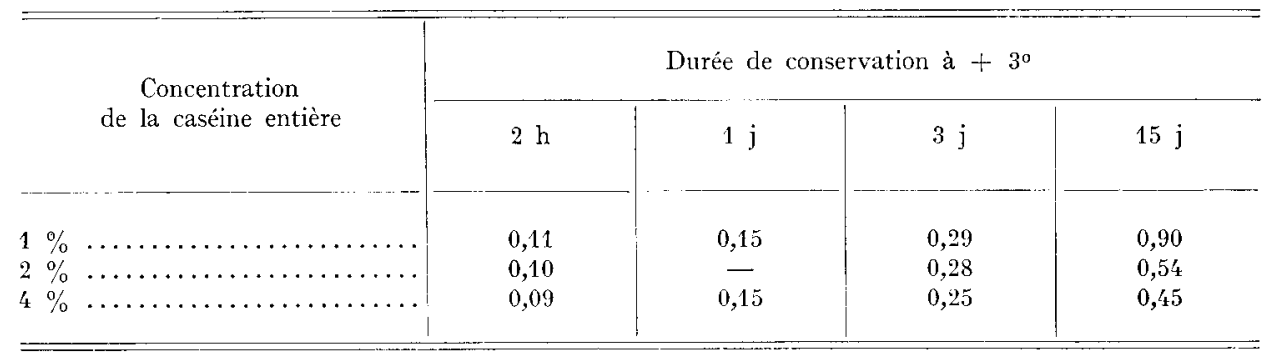

\section{II. - Étude des substances SOlubles, dútachées de la casérne $x$ PAR L'ACIDE TRICHLORACÉTIQUE ("NPN-O »), ET DE L'ACTION DE LA PRÉSURE SUR LA CASÉINE $x$ RÉSIDUELLE}

Nous avons fait les expériences suivantes avec la caséine $x$ :

a) Une solution à $2, \mathrm{I} 4 \mathrm{p}$. Ioo de caséine $x$ est additionnée d'un égal volume de TCA à $24 \mathrm{p}$. Ioo (concentration finale I $2 \mathrm{p}$. IOO). Le filtrat contient 0,0 I I $5 \mathrm{mg} \mathrm{N} / \mathrm{ml}$, ce qui représente $0,78 \mathrm{p}$. Ioo de $\mathrm{N}$-caséine.

b) La dialyse de ce filtrat, dans les conditions de la préparation du caséinoglycopeptide, montre que 27,4 p. Ioo des substances azotées restent dans le sac de dialyse. Les $3 / 4$ environ de ces substances sont donc éliminés. La partie non dia1ysable représente $0,2 \mathrm{I} 4 \mathrm{p}$. roo de $\mathrm{N}$-caséine.

c) Le précipité de caséine, obtenu dans la première opération, est lavé puis amené à pH 6,8 et dialysé. On obtient une solution contenant 2 p. Ioo de caséine $\varkappa$ dénaturée par TCA. Une partie de cette solution, précipitée à nouveau par TCA à I2 p. IoO, donne un filtrat dont le contenu en $\mathrm{N}$ représente $0,59 \mathrm{p}$. Ioo de $\mathrm{N}$-caséine. Une autre partie, soumise à l'action de la présure, se comporte comme la caséine originelle : elle donne un coagulum et le filtrat trichloracétique, obtenu après $40 \mathrm{mn}$ d'action de la présure $(0,03 \mathrm{UP} / \mathrm{ml})$ contient $8,43 \mathrm{p}$. Ioo de $\mathrm{N}$-caséine ; la solution initiale donnait, dans les mêmes conditions $8,75 \mathrm{p}$. IoO.

La dénaturation de la caséine par TCA ne modifie donc pas ses propriétés, en ce qui concerne la réaction de la présure. 
Le NPN que l'on sépare du mélange réactionnel, après l'action de la présure sur la caséine $x$, par précipitation avec TCA à I 2 p. Ioo renferme probablement le NPN-O ci-dessus, à côté du caséino-glycopeptide. Mais nous avons constaté qu'une petite partie du NPN traverse la membrane de dialyse.

On peut supposer que les substances dialysables proviennent de la fraction de la caséine qui est soluble dans TCA avant l'action de la présure; car la faible perte d'azote au cours de la dialyse paraît proportionnelle à la quantité de NPN-O comme le montre le tableau 3 . Ainsi, avec la caséine $x$, la perte d'azote est plus élevée qu'avec la caséine entière ou la caséine $\alpha$, mais la quantité de NPN-O est également plus élevée. Dans tous les cas, la proportion d'azote dialysable est un peu inférieure à celle du NPN-O.

TABLEAU 3

Dialyse des substances azotées non protéiques

(NPN-O et NPN-présure)

\begin{tabular}{|c|c|c|c|c|}
\hline \multirow{2}{*}{ Substances } & \multicolumn{2}{|c|}{ p. 100 de $\mathrm{N}$-caséine } & \multicolumn{2}{|c|}{ p. 100 de NPN-présure } \\
\hline & NPN-O & NPN-présure & NPN-O & N-dialysable \\
\hline $\begin{array}{l}\text { NPN }(12 \%) \text { de caséine entière } . \\
\text { NPN }(12 \%) \text { de caséine } \alpha \ldots \ldots \\
\text { NPN }(12 \%) \text { de caséine } \% \ldots \ldots .\end{array}$ & $\begin{array}{l}0,09 \\
0,11 \\
1,15\end{array}$ & $\begin{array}{l}1,75 \\
1,12 \\
10,0\end{array}$ & $\begin{array}{l}5 \\
10 \\
11,5\end{array}$ & $\begin{array}{r}3 \\
6 \\
10\end{array}$ \\
\hline
\end{tabular}

\section{Composition $d u$ "NPN-O ".}

Nous avons analysé la substance soluble dans l'acide trichloracétique à $x 2 \mathrm{p}$. Ioo et non dialysable, obtenue à partir de la caséine $x$ (sans action de la présure). La composition en acides aminés est donnée dans le tableau 4 , en p. Ioo de substances sèches et en rapports moléculaires, en prenant pour unité (Cys) et Phe.

Les rapports moléculaires sont très différents de ce qu'ils sont dans la caséine $x$. Les acides aminés aromatiques sont présents en faible proportion; il y a deux fois plus de Ileu que de Leu. Le NPN-O paraît avoir une composition en acides aminés intermédiaire entre celle de la caséine et celle du caséino-glycopeptide. On peut supposer que l'acide trichloracétique détache de la caséine un peptide comparable au caséino-glycopeptide. Ce peptide se trouverait dans le filtrat, à côté d'un peu de paracaséine qui apporte dans le mélange : Cys, Tyr et Phe. Sur cette base on peut déduire de la composition du produit initial ce qui reviendrait à la paracaséine ; on obtient ainsi les valeurs données dans le tableau 4 . On retrouve certaines caractéristiques du caséino-glycopeptide dans les rapports moléculaires que l'on peut établir sur la base Gly = Leu = I. Les différences portent principalement sur Pro et Glu et sur Lys qui disparait. On remarque que la proportion de la partie peptidique est faible dans le NPN-O.

L'examen électrophorétique sur papier rend plausible l'interprétation que nous avons faite de la composition en acides aminés. On observe la présence, dans le NPN-O, d'un composant migrant vers l'anode, comme le caséino-glycopeptide, à côté d'un autre composant peu mobile. 
TABIEAU 4

Composition en acides aminés du "NPN-O"

p. Iоo de la substance sèche

( $r$ : rapports moléculaires)

\begin{tabular}{|c|c|c|c|c|c|}
\hline & \multicolumn{2}{|c|}{ Produit initial } & \multicolumn{2}{|c|}{$\begin{array}{l}\text { Produit initial } \\
\text { après déduction } \\
\text { de la paracaséine } x\end{array}$} & \multirow{2}{*}{$\begin{array}{l}\text { Caséino- } \\
\text { glyco- } \\
\text { peptide } \\
r\end{array}$} \\
\hline & $\%$ & $r$ & $\%$ & $r$ & \\
\hline Asp $\ldots \ldots \ldots \ldots \ldots \ldots$ & 2,9 & 9 & 2,4 & 3 & 4 \\
\hline Thr $\ldots \ldots \ldots \ldots \ldots \ldots$ & 4,8 & 16 & 4,6 & 7 & 9 \\
\hline Ser $\ldots \ldots \ldots \ldots \ldots \ldots$ & 4,2 & 16 & 3,9 & 6 & 6 \\
\hline Glu ................. & 10,1 & 27 & 8,8 & 17 & 9 \\
\hline Pro...$\ldots \ldots \ldots \ldots$ & 2,0 & 7 & 1,4 & 2 & 7 \\
\hline Gly $\ldots \ldots \ldots \ldots \ldots$ & 0,6 & 3 & 0,5 & 1 & 1 \\
\hline 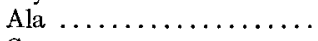 & 1,3 & 6 & 0,9 & 2 & 5 \\
\hline Cys $\ldots \ldots \ldots \ldots \ldots \ldots$ & 0,3 & 1 & 0,2 & 0,3 & 0 \\
\hline Val $\ldots \ldots \ldots \ldots \ldots \ldots$ & 3,3 & 11 & 3,0 & $4-5$ & 5 \\
\hline Ileu ................ & 2,3 & 7 & 1,9 & 3 & 5 \\
\hline Leu...$\ldots \ldots \ldots \ldots$ & 1,2 & 4 & 0,7 & 1 & 1 \\
\hline Tyr $\ldots \ldots \ldots \ldots \ldots$ & 0,7 & $1-2$ & 0 & 0 & 0 \\
\hline Phe ................. & 0,4 & 1 & 0 & 0 & 0 \\
\hline Lys $\ldots \ldots \ldots \ldots \ldots \ldots$ & 0,6 & $1-2$ & 0 & 0 & 3 \\
\hline Total $\ldots \ldots \ldots \ldots \ldots$ & 34,7 & & & & \\
\hline
\end{tabular}

JolLÈs et coll. (1961).

TABLEAU 5

Composition de la partie glucidique des NPN

p. Ioo de la substance sèche

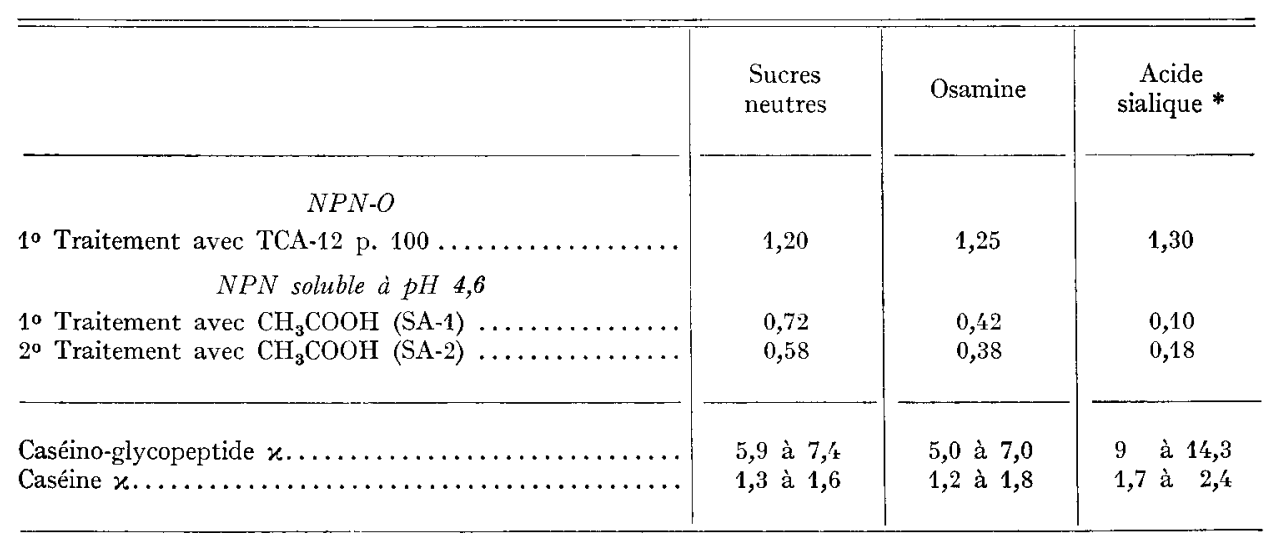

* En acide $\mathrm{N}$-acétylneuraminique. 
Ia composition de la partie non-peptidique est indiquée dans le tableau 5 . On voit que le NPN-O contient les trois types de glucides trouvés dans le caséino-glycopeptide (AIAIs et JOLLìs, I96I), mais en proportions beaucoup plus faibles. Ia somme des résultats analytiques est loin d'atteindre roo; nous ignorons la nature de 1'indosé.

\section{III. - ÉTUde DES SUBSTANCES SOlubles, DÉTAChÉES DE LA CASÉINE $\varkappa$ AU COURS DE LA PRÉCIPITATION A PH 4,6 PAR L'ACIDE ACÉTIQUE, ET DE L'ACTION DE LA PRÉSURE SUR LA CASÉINE $\varkappa$ RÉSIDUELLE}

Nous avons répété, avec l'acide acétique, en quantité juste suffisante pour abaisser à 4,6 le pH de la solution, les expériences faites précédemment avec l'acide trichloracétique. La solution de caséine $x$, à la concentration de I p. Ioo, a un pH voisin de 6,7 . Il faut environ $0,5 \mathrm{~m}$ éq d'acide acétique par gramme de caséine $x$ pour atteindre $\mathrm{pH} 4,6$ et faire floculer la protéine. On obtient un premier surnageant limpide, SA-I, séparé par centrifugation; il contient des substances azotées représentant 6,0 p. Ioo de l'azote ou 6,9 p. Ioo du poids de la caséine $x$ originelle. Le premier précipité est redissous dans 1'eau et 1'on effectue une deuxième précipitation comme ci-dessus. Le deuxième surnageant $\mathrm{SA}-2$ contient des substances azotées qui représentent 3,8 p. Ioo de 1 'azote de la caséine $x$ précipitée une première fois à $\mathrm{pH} 4,6$; ce qui correspond à 4,0 p. roo de l'azote de la caséine $x$ originelle, ou 4,7 p. Ioo de son poids.

Le chauffage des surnageants SA-I et SA-2 à $80^{\circ}$ pendant Io mn provoque l'apparition d'un trouble net; ceci ne se produit ni avec le filtrat trichloracétique contenant le NPN-O, ni avec la solution de caséine $x$.

$\mathrm{Au}$ cours de la dialyse contre l'eau distillée, on constate que $28 \mathrm{p}$. Ioo seulement de la substance $\mathrm{SA}$-I traverse la membrane; cette proportion est donc bien inférieure à celle que l'on observe avec le "NPN-O ».

I,e deuxième précipité a une consistance très ferme et se dissout difficilement dans l'eau, à pH 6,7, à moins d'employer un émulsionneur ("Ultra-Turrax »). Sur la solution nous avons fait agir la présure $(0,03 \mathrm{U} . \mathrm{P} . / \mathrm{ml})$; la réaction se produit comme avec la caséine $x$ originelle ; après la floculation le surnageant contient des substances solubles représentant $\mathrm{r} 8 \mathrm{p}$. Ioo en poids de la caséine traitée, alors que la caséine $x$ non dénaturée en donne $25 \mathrm{p}$. IOO en moyenne (BLONDEL, et ALAIS, I964).

Nous avons fait une autre expérience en traitant le deuxième précipité par l'urée $6 \mathrm{M}$, qui accélère sa dissolution. Après une longue dialyse, pour éliminer complétement l'urée et, éventuellement, des produits de dégradation, nous avons constaté que la présure réagissait normalement sur la caséine $x$ résiduelle ; après la coagulation, le surnageant contient des substances solubles représentant $33 \mathrm{p}$. Ioo de la caséine traitée.

Les examens électrophorétiques des substances solubles à pH 4,6 (sans dialyse), schématiquement représentées sur la figure $I$, montrent que la plus grande partie de la substance réagissant avec la ninhydrine ou avec le vert de lissamine, se trouve concentrée en une tache ayant une très faible mobilité par rapport aux acides aminés neutres. Avec le NPN résultant du deuxième traitement à $\mathrm{pH} 4,6$ on n'observe qu'une 
seule tache nette. Dans les detux examens il n'est pas apparu de constituant possédant une assez forte charge négative, comparable au caséino-glycopeptide. Après une dialyse prolongée, le constituant migrant vers la cathode disparait.
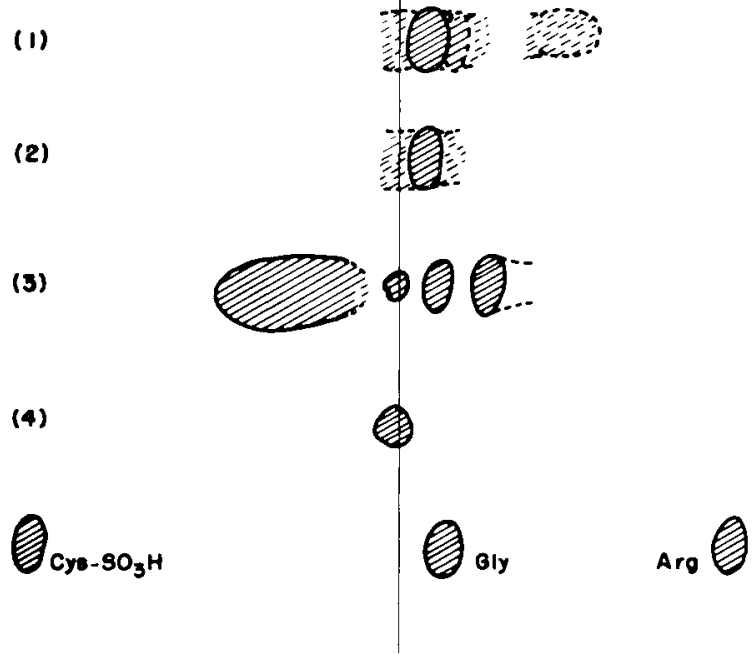

Fig. I. - Diagrammes d'électrophorèse sur papier

(I $5 \mathrm{v} / \mathrm{cm}, 2 \mathrm{~h}$, pli 6.5 , révélation par la ninhydrine)

(I) Substances solubles totales à pH $4,6(\mathrm{SA}-\mathrm{I})$.

(2) Substances solubles totales à pH 4,6 (SA-2).

(3) Substances solubles totales formées par la présure après un court temps de réaction sur la caséine $x$.

(4) Caséine $x$.

\section{Composition du "NPN $(p H 4,6)$ "}

La composition de la substance soluble à $\mathrm{pH} 4,6$ et non-dialysable est présentée dans les tableaux 5 et 6 . Le tablean 5 montre que cette substance contient très peu d'acide sialique, environ 20 fois moins que la caséine $x$; la teneur en sucres neutres et en osamine est également très faible. Des valeurs comparables ont été obtenues à partir des substances résultant d'un premier ou d'un deuxième traitement de la caséine $x$ à $\mathrm{pH} 4,6$. A ce point de vue, la substance " NPN (pH 4,6) " est très différente de celle que la présure détache de la caséine $x$.

Tous les acides aminés de la caséine $x$ sont présents dans le "NPN ( $\mathrm{pH} 4,6)$ " notamment les acides aminés aromatiques et soufrés, l'arginine et l'histidine; on sait que le caséino-glycopeptide ne contient pas ces acides aminés. Les rapports moléculaires, calculés sur la base Cys $=$ I sont proches de ceux que l'on a déterminés dans la caséine $x$ (JOLLìs et coll., I962). Bien que la proportion de la proline soit nettement plus forte et celle des acides aminés aromatiques plus faible dans le NPN que dans la caséine $x$, il y a une parenté évidente entre ces deux substances. Il est à noter qu'une analyse préliminaire de la substance SA-I, avant dialyse, avait révélé un fort excès des acides aminés basiques sur les acides aminés acides (28/12). 
La dialyse élimine un peptide basique, que l'on observe sur l'électrophorégramme. Dans la substance purifiée par dialyse et dans la caséine $x$ ces acides sont dans un rapport voisin (respectivement $25 / 59$ et $22 / 53$ ).

\section{TABLEAU 6}

Composition en acides aminés $d u$ "NPN (pH 4,6) 》

$p$. Iоo de la substance sèche

( $r$ : rapports moléculaires)

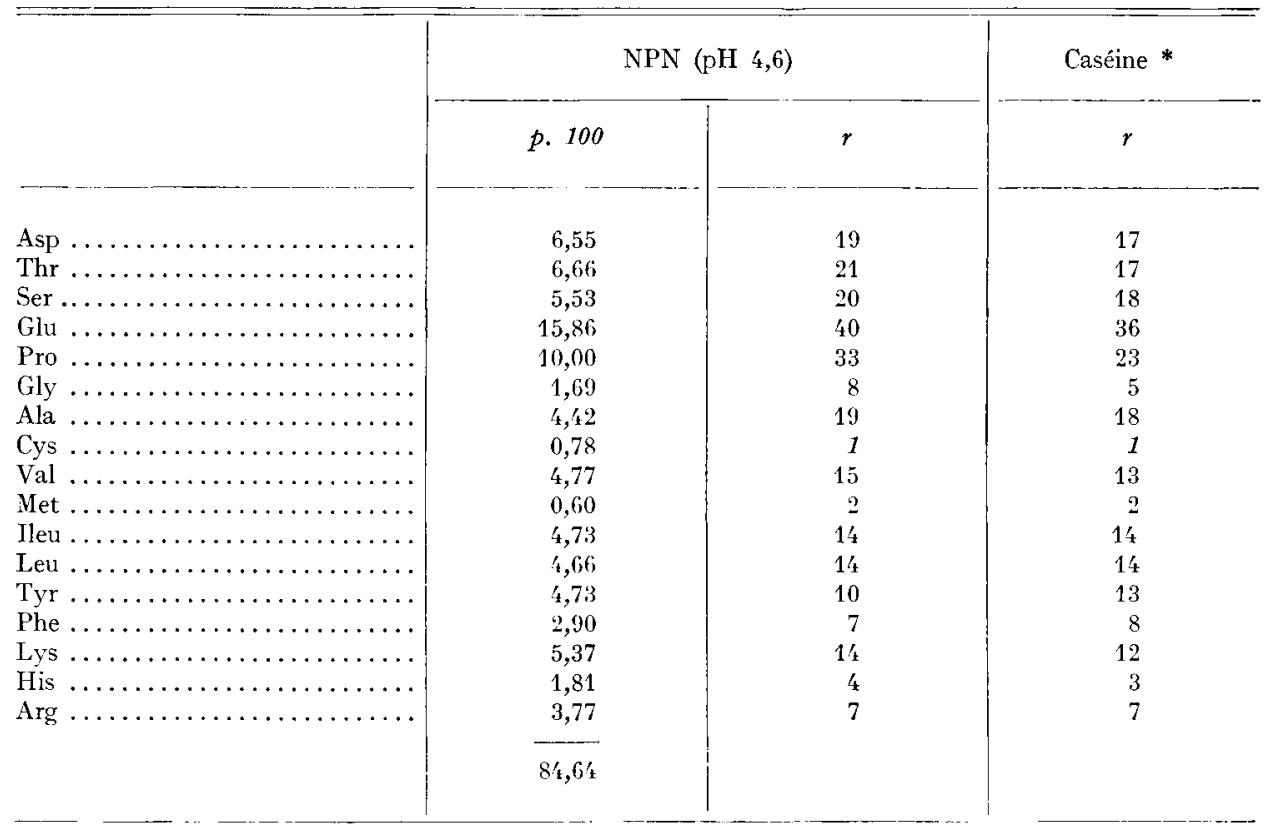

* P. JolLès et coll. (1962).

\section{DISCUSSION}

La simple précipitation isoélectrique des caséines n'est pas un traitement anodin; nos résultats confirment ceux d'autres auteurs, précédemment cités, concer_ nant la libération de substances peptidiques au cours de ce traitement. Nous avons montré qu'une dégradation comparable se produit lorsque l'on traite la caséine par l'acide trichloracétique, dans les conditions utilisées pour l'étude des réactions enzymatiques; cependant, les substances solubles libérées par l'acide trichloracétique (NPN-O) ont une composition différente de celles qui sont libérées à $\mathrm{pH} 4,6$ par l'acide acétique. Il ne s'agit pas simplement de la solubilité réelle de la protéine dans les réactifs acides, comme le démontrent les résultats analytiques et les examens électro- 
phorétiques. Le " NPN-O " contient un peptide acide et non dialysable, comme le caséino-glycopeptide (mais la teneur en glucides du NPN-O est faible) et le " NPN $(\mathrm{pH} 4,6)$ " contient un peptide basique dialysable. Cependant, dans cette dernière substance, le constituant dominant est proche de la caséine $\varkappa$ par sa composition en acides aminés.

Nos résultats ne nous permettent pas de conclure que les réactifs acides libèrent des fragments solubles en coupant une liaison principale, telle qu'une liaison peptidique. La formation de complexes relativement stables entre une protéine et des polypeptides est connue ; ces complexes peuvent être précipités par les sels et redissous sans décomposition; c'est ainsi qu'ont été purifiées des hormones (ACHER et coll., I960); elles sont séparées de la protéine support par l'acide trichloracétique à Io p. Ioo. La décomposition d'un complexe, avec rupture de liaisons secondaires par les réactifs acides, apporte une explication plausible dans le cas de la caséine entière ; on sait que des substances ayant un point isoélectrique élevé (jusqu'à 8,0 ) précipitent avec les caséines authentiques $\left(\alpha_{s}, \beta, x\right)$ à $\mathrm{pH} 4,6-4,7$. En ce qui concerne la caséine $x$, il faudrait supposer que de tels complexes résistent au traitement par 1'urée $6 \mathrm{M}$, qui intervient dans la préparation de cette protéine.

La caséine $x$ est le constituant le plus sensible à ces traitements. En considérant les valeurs présentées dans le tableau $I$, on peut supposer que le NPN formé à partir de la caséine entière provient uniquement de la fraction $x$; d'après les valeurs obtenues avec TCA à $\mathrm{I} 2 \mathrm{p}$. Ioo ou à $\mathrm{pH} 4,6$, la caséine entière contiendrait respectivement I7,5 ou I4 p. Ioo de caséine $x$. Ces proportions sont proches de celles précédemment déduites des études physiques (WAUGH et Von HIPPEL, I956) et chimiques (AlAIs, I962). La sensibilité particulière de la caséine $x$ au traitement à $\mathrm{pH} 4,6$ a été récemment observée par MARIER et coll., (I963); ils ont montré que de l'acide sialique, sous forme combinée, passait dans la solution tampon d'acétate.

BEEBY et Nitschmann (I963), en précipitant la caséine $x$ à $\mathrm{pH} 4,6$, par $\mathrm{HCl}$, ont isolé une substance glycopeptidique qu'ils considèrent comme très proche de celle qui résulte de l'action de la présure ou de l'action de l'urée sur cette caséine. D'autre part, ils considèrent que la caséine $x$ résiduelle, après le traitement à $\mathrm{pH} 4,6$ ou par l'urée, ressemble d'une façon "marquée " à la paracaséine. Nos expériences avec l'acide acétique ont conduit à des résultats différents. Nous essaierons plus tard de savoir si la nature de l'acide utilisé pour la précipitation à $\mathrm{pH} 4,6$ influe sur les résultats; mais il faut noter la très faible concentration de l'acide; dans nos expériences, le mélange final était à $0,005 \mathrm{M}$ en acide acétique, pour la première précipitation.

Nos résultats révèlent des différences entre les produits solubles libérés par la présure, d'une part, et par la précipitation à $\mathrm{pH} 4,6$ d'autre part. De plus, après deux traitements successifs à $\mathrm{pH}$ 4,6 (ayant détaché près de I2 p. Ioo de la substance originelle), la caséine $x$ résiduelle subit encore normalement l'action floculante et protéolytique de la présure (alors que la paracaséine $x$ ne la subit plus); il en est de même après le traitement de la caséine $x$ par l'urée. Il faut remarquer enfin que les traitements à $\mathrm{pH} 4,6$ ne détachent qu'une faible proportion des glucides de la

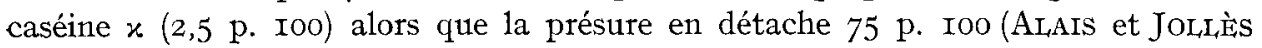
Ig6r).

Il découle de ces résultats que la présure et la précipitation à $\mathrm{pH} 4,6$ n'ont pas la même action sur la caséine $\varkappa$. D'autre part, il ne paraît pas possible 
qu'un peptide semblable au caséino-glycopeptide et en proportion comparable puisse être formé aux dépens des substances solubles à $\mathrm{pH} 4,6$. Nos résultats ne sont donc pas en faveur de l'hypothèse de BeEby et Nitschmann (Ig63), selon laquelle la présure détache, de la caséine $x$, en premier lieu, une fraction glycopeptidique par coupure d'une liaison secondaire, comme le ferait la précipitation à $\mathrm{pH} 4,6$ ou l'urée, le caséino-glycopeptide étant formé en second lieu par rupture d'une liaison de covalence.

L'action de l'acide trichloracétique sur la caséine $x$ ne peut non plus être assimilée à celle de la présure car, dans le premier cas, la caséine $\varkappa$ n'est pas transformée en paracaséine. La proportion de " NPN-O " varie avec les conditions de l'expérience. Nous avons observé qu'elle augmente au cours de la conservation de la caséine entière; la cause en est probablement la protéase étudiée par WARNER et POLLIS (1945), qui est fortement attachée à ce substrat. Dans une précédente communication (ALAIS, I 963), nous avons relevé des valeurs très variables selon les auteurs, en ce qui concerne la proportion de "NPN-O " avec la caséine $x$; il arrive même qu'elle soit supérieure à celle du NPN résultant de l'action propre de la présure, auxquelles le "NPN-O » vient s'ajouter. Dans nos précédentes études sur l'action de la présure, la proportion de " NPN-O » est faible et ne représente finalement que 2 p. Ioo du caséinoglycopeptide.

La solubilité apparente de la caséine humaine dans les réactifs acides est beaucoup plus élevée que celle des autres caséines entières. Nous n'avons pas encore étudié la fraction " NPN-O " provenant de la caséine humaine, mais on peut déjà souligner cet écart dans les proportions, qui révèle une nouvelle différence entre cette caséine et celle des ruminants (ALAIS et Joli,ès, Ig62).

Reçu pour publication en mars 1964 .

\section{REMERCIEMENTS}

Ce travail a bénéficié d'une subvention du Ministère de l'Agriculture des États-Unis (Cirant FG-FR-rı2; U. S. Public Iaw 480).

\section{SUMMARY}

\section{ACTION OF ACETIC AND TRICIILOROACETIC ACIDS ON CASEIN}

When different caseins are precipitated from solution by lowering the pH to 4.6 by the addition of acetic acid, and when they are precipitated by trichloroacetic acid at a final concentration of I 2 p. Ioo, peptide substances remain in solution. Their proportion depends on the type of casein and the experimental conditions. $\boldsymbol{x}$-casein is the constituent of whole casein of cow milk which is the most sensitive to the acidic reagents. Casein of human milk has also a relatively high solubility in these reagents. The proportion of these soluble substances in solutions of casein increases with time.

$\varkappa$-casein of cow milk has been studied in detail and the results have been interpreted taking into account the special properties of this protein which is the specific substrate for rennet. The proportion of soluble substances is $6 \mathrm{p}$. 100 with acetic acid and $0.75 \mathrm{p}$. 100 with trichloroacetic acid

Annales de Biologie animale. - 1964. 
(I2 p. Ioo with rennet). These substances formed during a second treatment with the same reagents. In both cases the residual $x$-casein reacts normally with rennet.

At $\mathrm{pH} 4.6$ a dialysable basic peptide is liberated along with a non-dialysable constituent which has some similarities with $x$-casein in the molecular ratios of its amino acids. With trichloroacetic acid there is a non-dialysable acidic peptide in solution along with a constituent which migrates little during electrophoresis (at $\mathrm{pH}$ 6.5); we have compared them to caseinoglycopeptide and to para-x-casens obtained by the action of rennet. In spite of some similarities, the low carbohydrate content of the substances soluble in the acid reagents, and above all the fact that the residual $x$-casein undergoes the normal reaction with rennet (it has not been changed to para-casein during treatment) show that the action of these reagents cannot be compared with to the action of rennet on the original $x$-casein.

\section{RÉFÉRENCES BIBLIOGRAPHIQUES}

Acher R., Light A., du Vignaud V., ig6o. Purification of oxytocin and vasopressin by Way of protein complex. J. Biol. Chem., 233, i16-120.

Alais C., et al. 1953. Das Lab und seine Wirkung auf das Casein der Milch. Helv. Chim. Acta, 36, I955-1968.

At.AIS C., I956. Étude des substances azotées non protéiques séparées de la caséine sous l'action de la présure. XIV Congr. Intern. Laiterie, 2, $823-839$.

Alais C., Jollès P., 196I. Étude comparée des caséino-glycopeptides formés par l'action de la présure sur les caséines de Vache, de Brebis et de Chèvre. II. Étude de la partie non peptidique. Biochim. Biophys. Acta, 51, 315-322.

Alais C., Jollès P., x962. Human casein and its caseino-glycopeptide. Nature, 196, 1098-1og9.

Alais C., Ig62. Étude de l'action enzymatique de la présure sur la caséine. Thèse, Paris.

Alais C., I963. Étude de la libération de l'azote, du phosphore et de l'acide sialique non protéiques, au cours de l'action de la présure sur la caséine. Ann. Biol. anim. Bioch. Biophys., 3, 391-404.

Beeby R., Nitschmann Hs., ig63. The disruption of the $x$-casein complex. J. Dairy Sci., 30, 7-16.

Blondel J., Alais C., 1964. (Communication en préparation).

Hammarsten O., I874. Úber den chemischen Verlauf bei der Gerinnung des Caseins mit Lab. Maly's J. ber. Tierchem., 4, $135^{-1} 45$.

Hammarsten O., 1876. Dans La Science Fromagère, par Beau M. et Bourgain C., Paris, 1926, p. I5.

Hipp N. J., et al. 1952. Séparation of $\alpha$-, $\beta$ and $x$-caseins J. Dairy Sci., 35, 272-281.

Jollès P., Alais C., Joll.ès J., 196r. Étude comparée des caséino-glycopeptides formés par action de la présure sur les caséines de Vache, de Brebis et de Chèvre. I. Étude de la partie peptidique. Biochim. Biophys. Acta, 51, 309-314.

Jollès P., Alais C., Jollès J., 1962. Amino-acid composition of $x$-casein. Arch. Biochem. Biophys., 98, 56-7.

Marier J. R., Tessier H., Rose D., ig63. Sialic acid as an index of $x$-casein content of Bovine Skimmilk. J. Dairy Sci., 46, 373-379.

MCKenzIE H. A., WAKE R. G., 196r. An improved method for the isolation of $x$-casein. Biochim. Biophys. Acta, 47, 240-242.

PIEZ K. A., Morris L., r960. An modified procedure for the automatic analysis of aminoacids. Anal. Biochem., 1, 187.

Quevenne T. A., I841. Mémoire sur le lait. Ann. Hyg. Publ. Paris.

Rondie C. J., Morgan W. T. J., 1955. The determination of glucosamine and galactosamine. Biochem. J., 61, 586-590.

Rowland S. J., 1938. The precipitation of the proteins in milk. J. Dairy Res., 9, 30-38.

Schultze H. E., Schmiedtrerger R., HAupt H., 1958. Untersuchungen über die gebundenen Kohlenhydrate. Biochem. Z., 329, 490-507.

Warner R. C., Pollis E., 1945. On the presence of proteolytic enzyme in casein. J. amer. Chem. Soc., 67, 529-532.

WARREN L., 1959. The thiobarbituric acid assay of sialic acid. J. Biol. Chem., 234, 1971-1975.

WaUgh D. F., V. HipPel P. H., 1956. $x$-casein and the stabilisation of casein micelles. J. amer. Chem. Soc., 78, 4576-4582. 